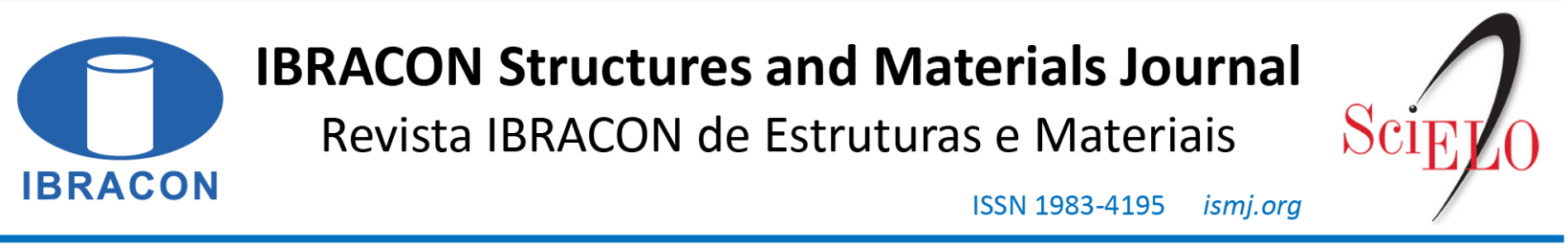

ORIGINAL ARTICLE

\title{
Structure and nanomechanical characterization of synthetic calcium-silicate-hydrate with poly-methacrylic acid
}

\section{Caracterização nanomecânica e estrutural do silicato de cálcio hidratado sintetizado com poli(ácido metacrílico)}

\author{
Fernando Pelisser ${ }^{\mathrm{a}}$ (D) \\ Philippe Jean Paul Gleize ${ }^{\mathrm{a}}$ (D) \\ Alexandre Mikowski ${ }^{\mathrm{b}}$ (D)
}

${ }^{a}$ Universidade Federal de Santa Catarina - UFSC, Departamento de Engenharia Civil, Florianópolis, SC, Brasil

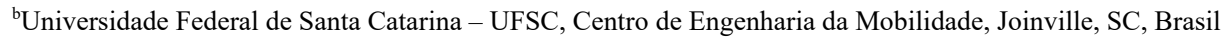

Received 29 November 2018 Accepted 20 February 2020

\begin{abstract}
The principal phase of hardened Portland cement pastes is calcium silicate hydrate (C-S-H), which influences the physical and mechanical properties of construction materials. In this work, calcium silicate hydrate (C-S-H) was synthesized, with the addition of poly-methacrylic acid with sodium (PMA), for the development of $\mathrm{C}-\mathrm{S}-\mathrm{H} /$ polymer nanocomposites. Among the polymers available, PMA is indicated in the literature as one of those viable for producing C-S-H/polymer complexes. However, no consensus exists regarding the type of interaction this produces. The resulting compounds were characterized by XRD, FT-IR, TGA, carbon content (CHN), TEM, SEM and elastic modulus and hardness were measured by instrumented indentation. A significant change was verified in the nanomechanical properties of C-S-H with PMA, resulting in reduction in the elastic modulus and hardness. The set of results presented do not confirm the intercalation of PMA in the interlayer space of C-S-H, but presented evidence of the potential for intercalation, since changes in the microstructure clearly occurred.
\end{abstract}

Keywords: calcium silicate hydrate, poly-methacrylic acid, nanocomposites, nanoindentation.

How to cite: F. Pelisser, P. J. P. Gleize, and A. Mikowski. "Structure and nanomechanical characterization of synthetic calcium-silicate-hydrate with poly-methacrylic acid”, Rev. IBRACON Estrut. Mater., vol. 13, no. 5, e13509, 2020, https://doi.org/10.1590/S1983-41952020000500009

\section{INTRODUCTION}

It is well known that calcium silicate hydrate (C-S-H), the main product from Portland cement hydration, has a significant influence on most physical and mechanical properties of cement-based materials. C-S-H is considered a lamellar, crystalline semi-continuum and an inherently complex material, particularly in relation to its "bond" nature forces - ionocovalent forces between individual C-S-H layers or C-S-H layer stacks, separated by strongly localized calcium ions and water molecules. 
It consists of order-disorder lamellae stacking of particles, where each lamellae is formed by stacking sheetsand each sheet has a central $\mathrm{Ca}-\mathrm{O}$ sheet that has silicate chains on both sides, which are kinked with a periodicity of three tetrahedral. These chains are called dreierketten [1] and indicate the degree of polymerization of C-S-H. Its structure interferes with the interplanar distance, density [2] and the mechanical behavior of hydrated calcium silicate [3], [4]. C-S-H is similar to the tobermorite-jennite like nanostructure crystal [1], with a complex structure; it is intrinsically fragile with a low flexural strength [5]. The complex nanostructure of C-S-H makes it an excellent candidate for the manipulation and control of its properties, through the intercalation of organic molecules, for the fabrication of C-S-H/polymer nanocomposites [6]. The advancement of nanoscience through the development of C-S-H/nanocomposites is important for the production of materials that are more efficient in relation to the binding forces [7]-[9], thus improving the tensile strength and avoiding the cracking problems inherent to concrete and mortar, which are widely used by the construction industry. Nature has shown that the mixture of organic and inorganic materials is a potential route for the elaboration of more efficient materials; teeth and bones are good examples.

C-S-H/polymer nanocomposites have been successfully synthesized [10]-[19]. Observation of an increase in the interlamellar spacing has been reported, which is explained by the intercalation of polymers between the sheets of C-S-H. Studies have also concluded that polymer intercalation depends on the C-S-H Ca/Si molar ratio, the method of synthesis and the type of organic polymers. Among the polymers tested, anionic polymers were one of the most successful at producing C-S-H/polymer nanocomposites [12], [14], [15], for example poly(acrylic acid) and poly-methacrylic acid. A study [17] has provided evidence for the adsorption and intercalation of polyethylene glycol (PEG) polymers on the surface and within the interlayer spaces of the C-S-H structure (altering the interlayer spacing from $1.5 \mathrm{~nm}$ to $4.5 \mathrm{~nm}$ ). It has also been reported that the presence of PDC in $0.8 \mathrm{Ca} / \mathrm{Si} \mathrm{C}-\mathrm{S}-\mathrm{H}$ affects both its nano and mesostructure: the broadening and slight shift in the 002 basal reflections (XRD) and the alteration in C-S-H Si-O-Si bonding (FT-IR) indicate that a part of the PDC is intercalated between the C-S-H lamellae, and; the remaining PDC is probably adsorbed on the surface or in the void space left by the C-S-H particles, affecting its packing density, consequently, significant alterations in the mechanical properties of C-S-H in the presence of PDC were verified [18]. Research evaluating the effect of PVA polymer verified modifications in the interlayer spacing of the C-S-H, such that it increased between $1.53 \mathrm{~nm}$ and $1.70 \mathrm{~nm}$, and significant change in the nanomechanical properties of C-S-H occurred in the presence of PVA, resulting in a strong reduction in elastic modulus and hardness [19].

Although numerous studies have observed changes in nanostructures and have associated these changes with the mechanical behavior of the materials, the mechanical tests using instrumented indentation in C-S-H/PMA complexes have never been performed. Thus, this study evaluated the chemical and micro-nanomechanical properties of the synthesis of C-S-H modified with PMA polymer, in order to contribute to the development of C-S-H/polymer nanocomposites.

\section{MATERIALS AND EXPERIMENTAL PROGRAM}

C-S-H and C-S-H/PMA samples were produced by the direct precipitation method [12]. PMA polymer solution was used at

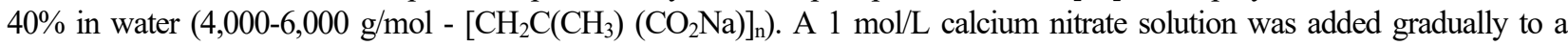
$0.22 \mathrm{~mol} / \mathrm{L}$ solution of sodium silicate with the polymer (except for pure $\mathrm{C}-\mathrm{S}-\mathrm{H}$ ) predissolved in $\mathrm{CO} 2$-free deionized water to achieve a $2.1 \mathrm{Ca} / \mathrm{Si}$ ratio. Chemical analysis by XRF (Table 1) showed that the final $\mathrm{Ca} / \mathrm{Si}$ ratio (1.62 for C-S-H and 1.73 for C$\mathrm{S}-\mathrm{H} / \mathrm{PMA}$ ) remained proportional to the initial project value. The PMA concentration was $0.5 \mathrm{~g} / \mathrm{g}$ Ca salt [12]. The total water:solid ratio was $20: 1$. The $\mathrm{pH}$ of the mix was maintained between 13.1 and 13.3 with a $\mathrm{NaOH}$ solution $(10 \mathrm{~mol} / \mathrm{L})$. After maintaining the suspension at $60^{\circ} \mathrm{C}$ for 35 days under gentle stirring in a $\mathrm{CO}_{2}$-free atmosphere, the precipitates were vacuumfiltered and then washed with acetone and $\mathrm{CO}_{2}$-free deionized water to eliminate the residual polymers and sodium nitrate ions. Next, the precipitates were dried at $60^{\circ} \mathrm{C}$ in a vacuum oven for 14 days. One part of the precipitate was ground in an agate mortar and sieved (\# $75 \mu \mathrm{m}$ ) for XRD, XRF, FT-IR, TGA and carbon content (CHN), while the other part (small irregular particles) was vacuum-impregnated in $2 \mathrm{~cm} \times 2 \mathrm{~cm}$ cylinders with a low viscosity resin and cut with a diamond saw for nanoindentation tests. For TEM observations (JEOL, $100 \mathrm{kV}$ ), the ground precipitates (before drying) were dispersed in ethanol and dripped onto a 400-mesh copper grid covered by a carbon film, after which the grid was placed in a vacuum desiccator for $24 \mathrm{~h}$.

Table 1. Chemical analyses of the C-S-H and C-S-H/PMA (XRF).

\begin{tabular}{cccccc}
\hline Oxide (mass \%) & $\mathbf{S i O}_{2}$ & $\mathbf{C a O}$ & $\mathbf{A l}_{2} \mathbf{O}_{3}$ & $\mathbf{F e}_{2} \mathbf{O}_{3}$ & $\mathbf{L O I}$ \\
\hline C-S-H & 24.56 & 37.15 & 0.04 & $<0.01$ & - \\
\hline C-S-H/PMA & 13.66 & 22.39 & $<0.01$ & $<0.01$ & - \\
\hline
\end{tabular}

The cylinder surface was then ground with silicon carbide papers and polished with diamond pastes (four stages of increasing fineness) to obtain a very flat, smooth surface finish. After each grinding/polishing stage, the samples were placed in an ultrasonic bath to remove the dust and diamond particles left on the surface or in the porous structure. 
Nanoindentation was performed using a Nanoindenter XP (MTS System). The unpolished surface of the cylindrical specimens was carefully cut with the diamond saw into sections that were 5-6 mm thick. Twelve indentations were performed in each sample in three different regions (for each region, four individual indentations were performed in $2 \times 2$ matrices, with $20 \mu \mathrm{m}$ spacing) by applying five loading cycles of $2,4,8,16$, and $32 \mathrm{mN}$ in each indented location (matrix 1). An additional test was performed using higher loads (matrix 2) to evaluate both the nano- and microstructure of the material over a larger area, verify the homogeneity of the material and make marks that would be visible under SEM, thus achieving a more in-depth interpretation of the results by combining the characteristics of the microstructure, morphology and fractures, with the nanomechanical properties. In this case, a $2 \times 3$ points matrix was used up to a load of $512 \mathrm{mN}(1,2,4,8,16,32,64,128,256,512 \mathrm{mN})$. Loading was applied linearly for $10 \mathrm{~s}$. The maximal load $\left(\mathrm{P}_{\max }\right)$ was then maintained for $5 \mathrm{~s}$, and unloading occurred over an additional $10 \mathrm{~s}$. Hardness $(\mathrm{H})$ is defined as the mean pressure that a material can support under load, and is determined by [20], [21]:

$H=\frac{P_{\max }}{A\left(h_{c}\right)}$

Where $\mathrm{P}_{\max }$ is the maximum applied load and $\mathrm{A}\left(\mathrm{h}_{\mathrm{c}}\right)$ is the projected contact area function which corrects for the Berkovich tip rounding effect.

The elastic modulus of the material is determined by [22]:

$$
E=\frac{1-v^{2}}{\left(\frac{1}{E_{r}}-\frac{1-v_{i}^{2}}{E_{i}}\right)}
$$

where, $\mathrm{E}_{\mathrm{r}}$ is the reduced elastic modulus, $\mathrm{E}_{\mathrm{i}}$ and $v_{\mathrm{i}}$ are the indenter elastic modulus and Poisson ratio, and $\mathrm{E}$ and $v$ are the elastic modulus and Poisson ratio of the material respectively. For diamond, $E_{i}=1141 \mathrm{GPa}$ and $v_{i}=0.07$ [20], [21]. Based on relationships developed by Sneddon [23], an expression was derived for the reduced elastic modulus, $\mathrm{E}_{\mathrm{r}}$ [20], [21]:

$E_{r}=\frac{\sqrt{\pi}}{2 \beta} \frac{S}{\sqrt{A\left(h_{c)}\right.}}$

where $\mathrm{S}=(d P / d h)$ is the stiffness obtained experimentally from the upper part of the unloading curve and $\beta$ is a constant dependent on the indenter geometry, being equal to 1.034 for a triangular symmetry [20], [22]. After nanoindenter testing, the sample was removed, coated with a gold layer and examined by SEM.

XRD was performed to detect shifts in the C-S-H 002 basal reflections, which are due to polymer intercalation. A Philips X'Pert instrument was used that operates with $\mathrm{Cu} K \alpha$ radiation $(\lambda=1.5418 \AA)$ with an output of $40 \mathrm{kV}$ and $30 \mathrm{~mA}$. Scanning was performed from $2^{\circ}$ to $10^{\circ}(2 \theta)$ in $0.02^{\circ}$ steps, with a collection time of $5 \mathrm{~s}$ per step. A Perkin-Elmer 16PC Fourier transform-infrared spectrometer (FT-IR) was used in direct transmission mode ranging from 4000 to $400 \mathrm{~cm}^{-1}\left(4 \mathrm{~cm}^{-1}\right.$ resolution), and the carbon content was determined by $\mathrm{CHN}$ (carbon, hydrogen, nitrogen - EA $1100 \mathrm{CE}$ Instruments) elemental analysis. The thermogravimetric analysis (TGA) was performed on samples of approximately $20 \mathrm{mg}$, using a Shimadzu TGA-50, heating at $10^{\circ} \mathrm{C} / \mathrm{min}$ from 0 to $900^{\circ} \mathrm{C}$ in a nitrogen atmosphere at a flow rate of $100 \mathrm{ml} / \mathrm{min}$.

\section{RESULTS AND DISCUSSION}

\subsection{Chemical analysis}

C-S-H formation was observed with and without the addition of PMA (Figure 1). C-S-H showed peaks at $15.3 \AA$ and $12.2 \AA$, while in the C-S-H/PMA mixture, a small increase in the interplanar distance of $16.4 \AA$ was observed, with peaks at $11.4 \AA$ and $10 \AA$. The peak at $10 \AA$ could refer to the formation of either sodium acetate $\left(\mathrm{CH}_{3} \mathrm{COONa}\right)$ or sodium silicate $\left(\mathrm{Na}_{2} \mathrm{O} . \mathrm{SiO}_{2}\right)$. 


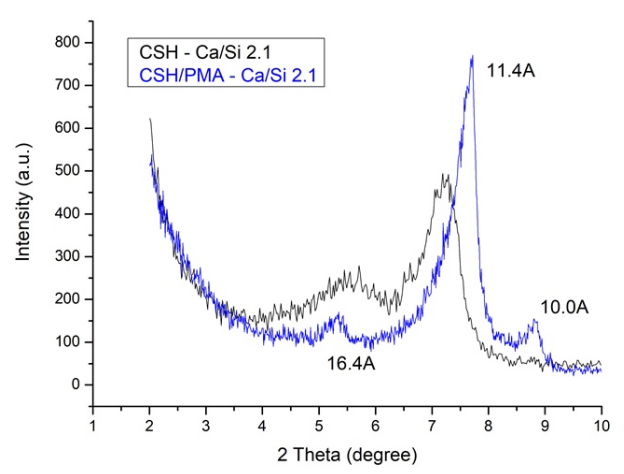

Figure 1. XRD spectra of C-S-H and C-S-H/PMA.

FT-IR spectra analysis verified the presence of the polymer in bonds represented by the bands 2970, 1419, 1458, 1470 and $1250 \mathrm{~cm}_{1}$ (Figure 2). Hydroxyl ions, nitrate, $\mathrm{Q}^{2}$ and $\mathrm{Q}^{1}$ were observed for C-S-H/PMA (Figure 2, Table 2). However, there are two bands for C-S-H/PMA at 957 and $910 \mathrm{~cm}^{-1}$, and essentially one that refers to the $\mathrm{Q}^{2}$ bond, at $910 \mathrm{~cm}^{-1}$, for C-S-H, which indicates an increase in the $\mathrm{Q}^{2} / \mathrm{Q}^{1}$ ratio and consequently, greater chain lengths and polymerization in the dreierketten region, with the addition of PMA. Very similar behavior was observed by Beaudoin et al. [17], in their research on nanocomposite C-S$\mathrm{H} /$ polymers (polyethylene glycol and hexadecyltrimethylammonium) using the NMR technique.

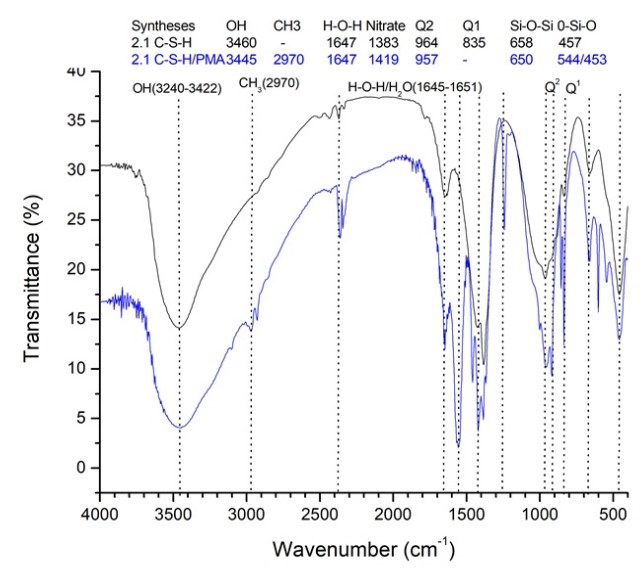

Figure 2. FT-IR spectra of C-S-H and C-S-H/PMA.

Table 2. Selected FT-IR bands of C-S-H and C-S-H/PMA.

\begin{tabular}{|c|c|c|c|}
\hline \multirow[b]{2}{*}{ Assignment of vibrational spectra } & \multicolumn{3}{|c|}{ Bands $\left(\mathrm{cm}^{-1}\right)$} \\
\hline & References & $2.1 \mathrm{C}-\mathrm{S}-\mathrm{H}$ & 2.1 C-S-H /PMA \\
\hline $\mathrm{OH}$ & $3268-3375^{(1)}$ & 3508 & 3445 \\
\hline $\mathrm{CH}_{3}$ & $2925^{(1)}$ & - & 2970 \\
\hline Nitrate & $2359^{(2)}$ & 2359 & 2359 \\
\hline $\mathrm{H}-\mathrm{O}-\mathrm{H}$ & $1651^{(1)}$ & 1618 & 1647 \\
\hline Nitrate $/ \mathrm{CO}_{2}$ & $1400 / 1434^{(2,1)}$ & $1385 / 1420$ & $1419 / 1458$ \\
\hline $\mathrm{C}=\mathrm{O}-\mathrm{OR}$ & $1434^{(1)}$ & - & 1419 \\
\hline $\mathrm{Q}^{2}$ & $969^{(3)}$ & 964 & 957 \\
\hline $\mathrm{Q}^{2}$ & $903^{(3)}$ & 900 & 910 \\
\hline $\mathrm{Q}^{1}$ & $814^{(3)}$ & 835 & 835 \\
\hline$\delta(\mathrm{Si}-\mathrm{O}-\mathrm{Si})$ & $672^{(3)}$ & 651 & 650 \\
\hline$\delta(\mathrm{O}-\mathrm{Si}-\mathrm{O})$ & $477^{(3)}$ & 457 & $544 / 453$ \\
\hline- & $\begin{array}{c}1647,1539,1472,1416,1350 \\
1207,1101^{(2)}\end{array}$ & - & $\begin{array}{c}1553,1460,1419,1380,1350, \\
1242^{(2)}\end{array}$ \\
\hline
\end{tabular}


Thermal analyzes (TGA) also showed changes in the structure of C-S-H/PMA in relation to C-S-H. Total mass loss was $15.5 \%$ higher for C-S-H/PMA (Figure 3), which is in agreement with the measured carbon content of $16.3 \%(\mathrm{CHN})$. Analysis also verified that C-S-H, C-S-H/PMA and PMA lost mass in two major regions: in region 1 , from 25 to $250^{\circ} \mathrm{C}$, both mixtures showed similar behavior; while in region 2 , between 250 and $550^{\circ} \mathrm{C}$, PMA polymer was degraded at two temperatures, above $400^{\circ} \mathrm{C}$ and above $650^{\circ} \mathrm{C}$. C-S-H/PMA did not follow this decomposition, however, rather it showed gradual loss of mass from $300^{\circ} \mathrm{C}$, different from C-S-H (Figure 3, Table 3). According to Mojumdar and Raki [15], these findings indicate the trapping and intercalation of the polymer within the C-S-H nanostructure.

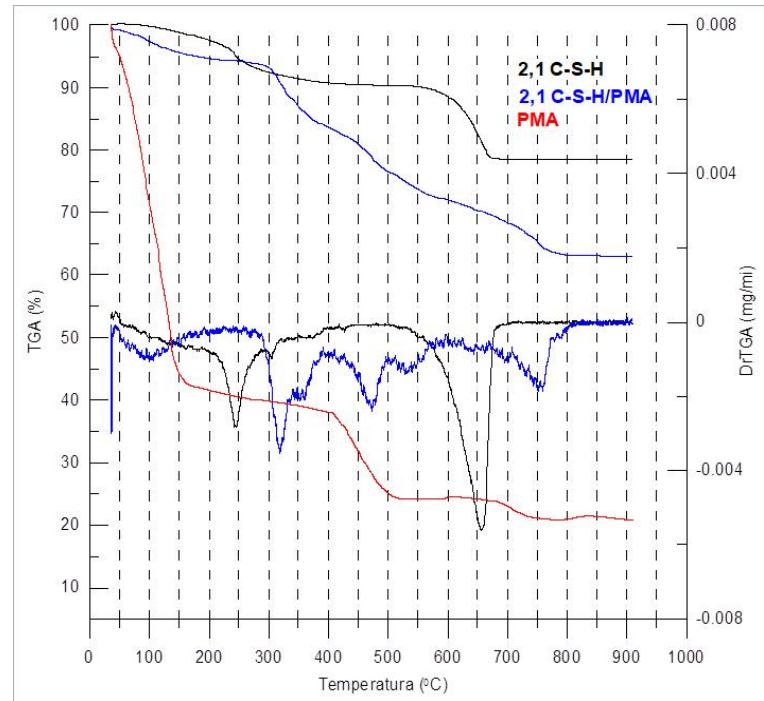

Fig. 3 TG/DTG to C-S-H, C-S-H/PMA and PMA

Table 3. Thermogravimetric analysis to C-S-H, PMA and C-S-H/PMA.

\begin{tabular}{cc}
\hline Material & DTG $/{ }^{\circ} \mathbf{C}$ \\
\hline C-S-H & 240,630 \\
\hline PMA & $100,446,707$ \\
\hline C-S-H/PMA & $106,324,453,532,718$ \\
\hline
\end{tabular}

\subsection{Micro-nanomechanical and morphological properties}

The nanomechanical properties of elastic modulus and hardness of C-S-H/PMA and C-S-H samples are shown by the following results:

- Results of the three indentation matrices for C-S-H/PMA (Figure 4a - elastic modulus E, Figure $4 \mathrm{~b}$ - hardness H);

- Mean results for elastic modulus (Figure 5a) and hardness (Figure 5b), comparing C-S-H/PMA and C-S-H for the indentation matrix with loading up to $32 \mathrm{mN}$;

- Example of load-penetration curves $(2 \mathrm{mN})$ measured by nanoindentation on samples prepared with C-S-H/PMA and C-S-H (Figure 6).

- Load-penetration curves $(2-32 \mathrm{mN})$ obtained by nanoindentation on samples prepared with C-S-H/PMA and C-S-H (Figure 7).

- Mean results for elastic modulus (Figure 8a) and hardness (Figure 8b), comparing C-S-H/PMA and C-S-H for the indentation matrix with loading up to $512 \mathrm{mN}$, which was then visualized under SEM (Figure 9). 

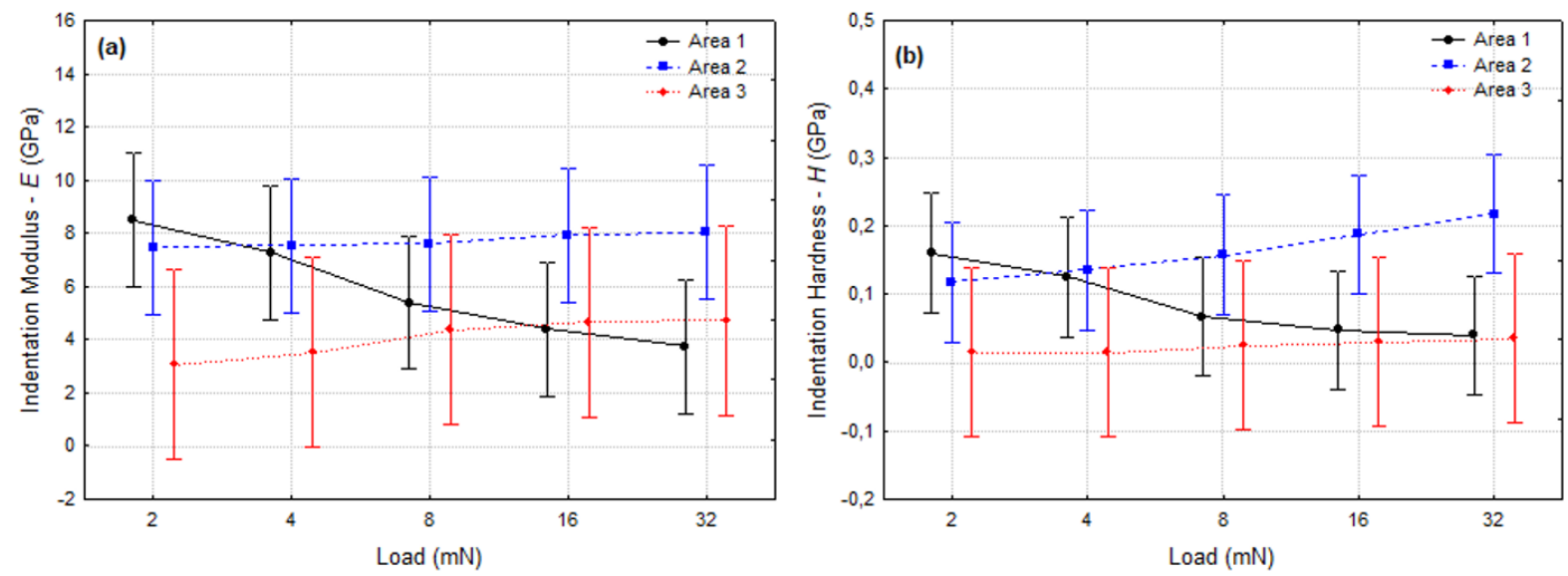

Figure 4. Micro-nanomechanical properties (elastic modulus and hardness) of C-S-H/PMA in specific areas.
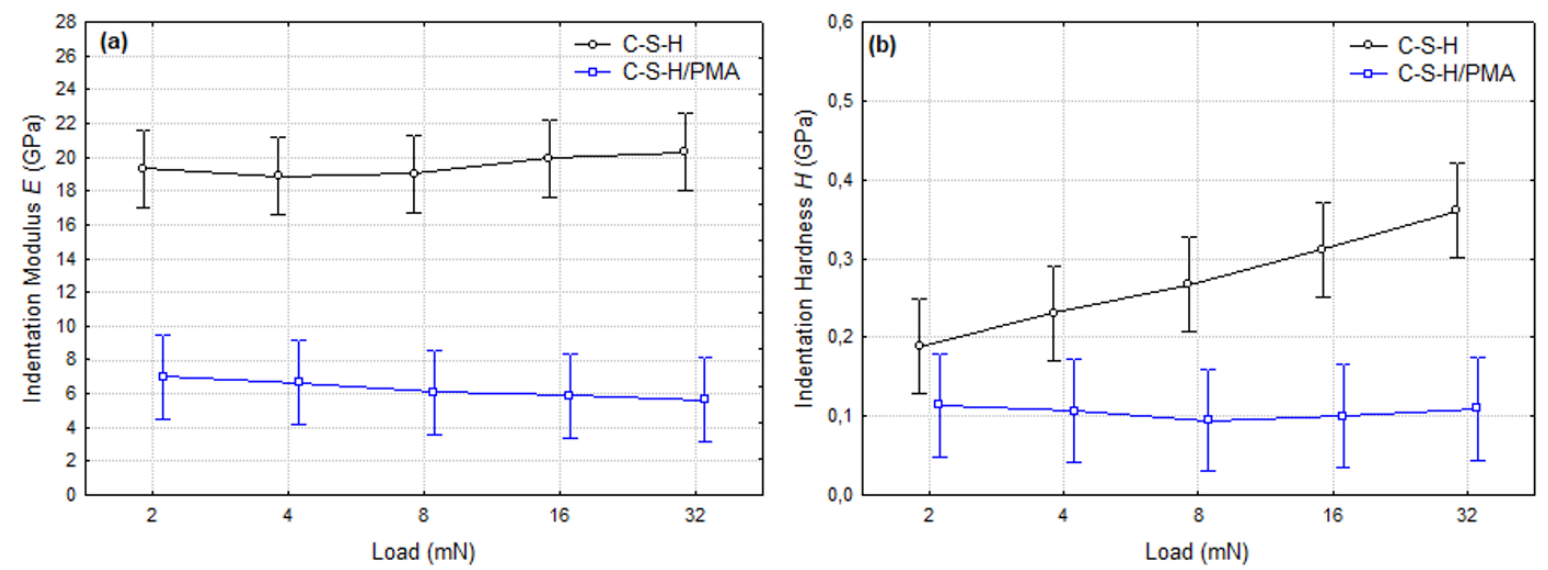

Figure 5. Elastic modulus - E (a) and hardness - H (b) vs applied load - P of C-S-H and C-S-H/PMA until 32 mN (matrix 1).

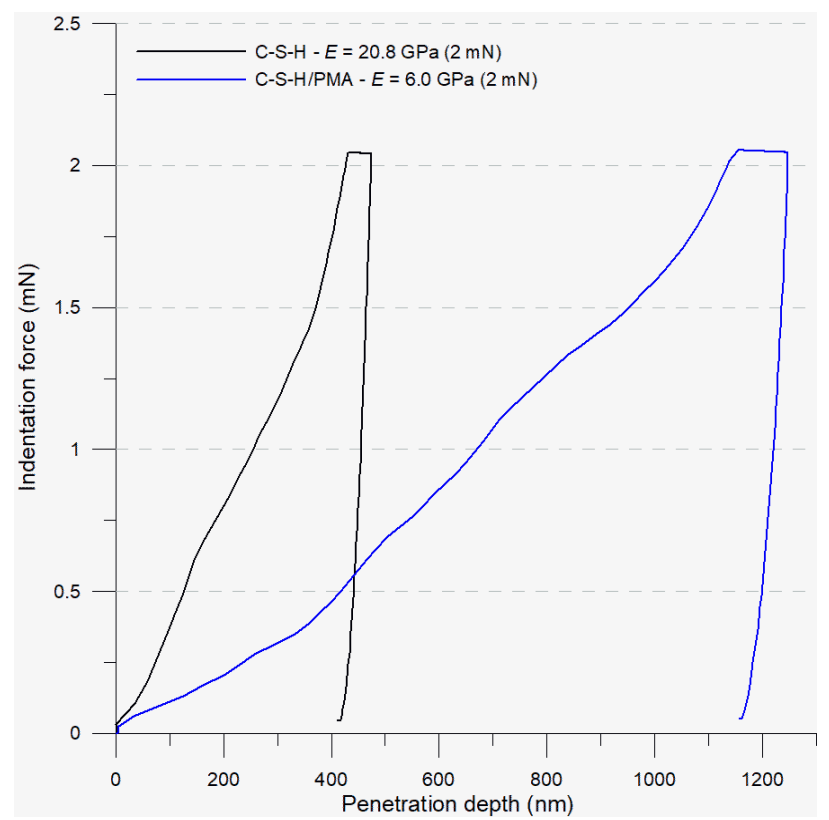

Figure 6. Example of load-penetration curves $(2 \mathrm{mN})$ measured by nanoindentation on samples C-S-H and C-S-H/PMA. 


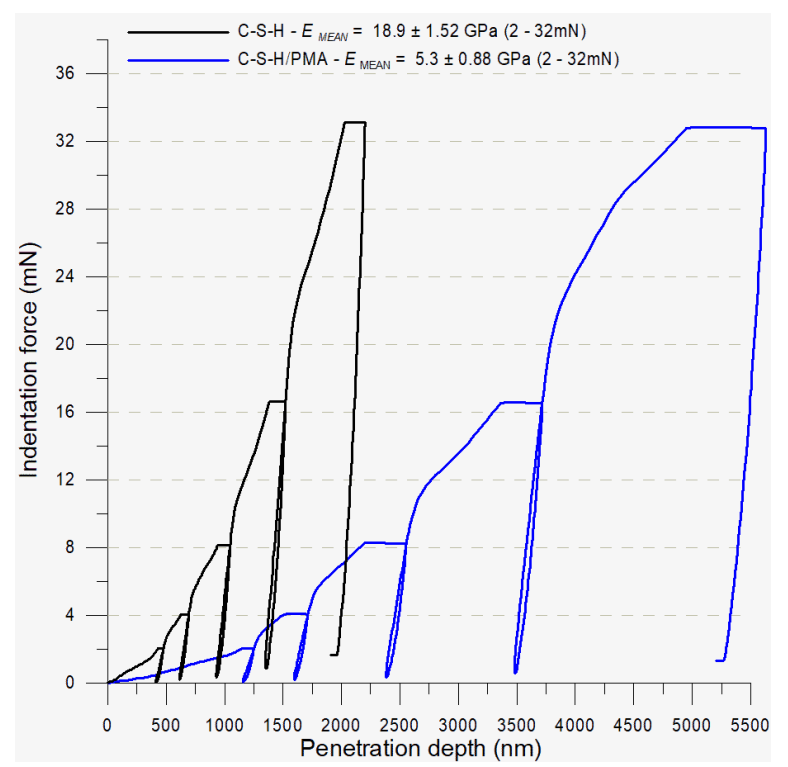

Figure 7. Load-penetration curves $(2-32 \mathrm{mN})$ obtained by nanoindentation on samples C-S-H and C-S-H/PMA.
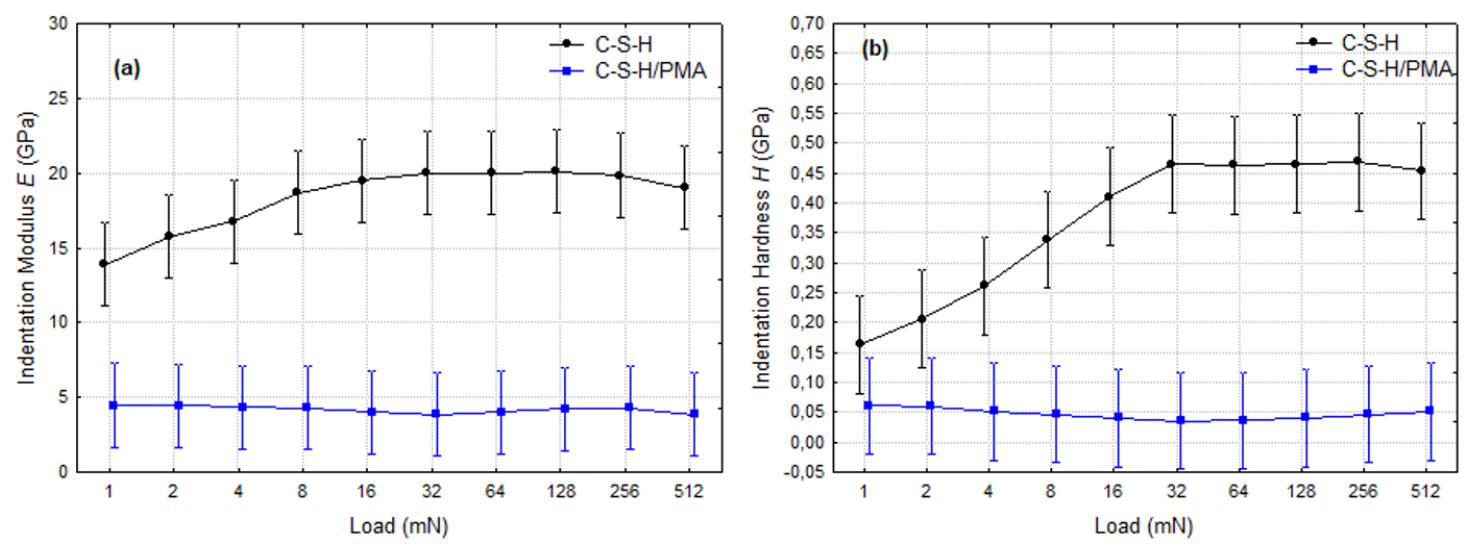

Figure 8. Elastic modulus - E (a) and hardness - H (b) vs applied load - P of C-S-H and C-S-H/PMA until 512 mN (matrix 2).

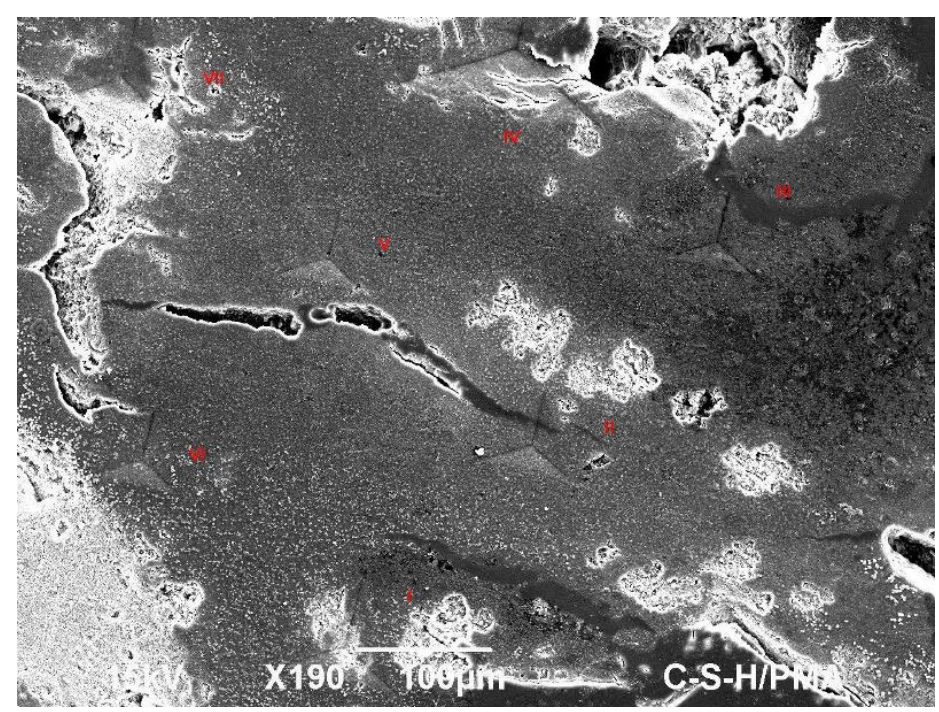

Figure 9. C-S-H/PMA SEM micrograph showing 5 indentations (matrix 2). 
A clear difference between C-S-H and C-S-H/PMA mechanical characteristics was determined (Figure 5). The mean elastic modulus and hardness values for the first series of measurements (matrix 1) were $19.5 \pm 4.5 \mathrm{GPa}$ and $0.27 \pm 0.12 \mathrm{GPa}$ for C-S-H and 6.25 $\pm 2.7 \mathrm{GPa}$ and $0.10 \pm 0.09 \mathrm{GPa}$ for C-S-H/PMA (Table 4), indicating the nanostructural alteration. Observation verified that no significant difference occurred between the applied loads in matrix 1 (loaded up to $32 \mathrm{mN}$ ), confirming that the effect of surface roughness was not significant (Table 5). Moreover, the SEM micrograph of five C-S-H/PMA indented regions (Figure 9, Table 6), in matrix 2 (load up to $512 \mathrm{mN}$ ), exhibited a reasonably regular surface at each point. Visualization of the indented region is an important tool for interpreting and analyzing the results obtained.

Table 4. Elastic modulus and hardness of C-S-H and C-S-H/PMA for different loads.

\begin{tabular}{cccccc}
\hline \multicolumn{2}{c}{ Variables / Results } & \multicolumn{2}{c}{ Matrix 1 } & \multicolumn{2}{c}{ Matrix 2 } \\
\hline Material & Load & $\mathrm{E}(\mathrm{GPa})$ & $\mathrm{H}(\mathrm{GPa})$ & $\mathrm{E}(\mathrm{GPa})$ & $\mathrm{H}(\mathrm{GPa})$ \\
& $2 \mathrm{mN}$ & $19.3 \pm 1.2$ & $0.19 \pm 0.05$ & $15.8 \pm 0.6$ & $0.20 \pm 0.08$ \\
\cline { 2 - 6 } C-S-H & $32 \mathrm{mN}$ & $20.3 \pm 3.9$ & $0.36 \pm 0.11$ & $20.0 \pm 3.7$ & $0.47 \pm 0.15$ \\
& $512 \mathrm{mN}$ & - & - & $19.0 \pm 1.6$ & $0.45 \pm 0.09$ \\
& Average & $19.5 \pm 4.5$ & $0.27 \pm 0.12$ & $18.4 \pm 4.3$ & $0.37 \pm 0.16$ \\
& $2 \mathrm{mN}$ & $6.34 \pm 0.83$ & $0.10 \pm 0.03$ & $4.43 \pm 1.47$ & $0.06 \pm 0.02$ \\
\cline { 2 - 6 } C-S-H/ PMA & $32 \mathrm{mN}$ & $5.65 \pm 2.22$ & $0.11 \pm 0.10$ & $3.83 \pm 1.33$ & $0.04 \pm 0.02$ \\
\cline { 2 - 6 } & $512 \mathrm{mN}$ & - & - & $3.84 \pm 0.78$ & $0.05 \pm 0.01$ \\
& Average & $6.25 \pm 2.7$ & $0.10 \pm 0.09$ & $4.17 \pm 1.2$ & $0.05 \pm 0.02$ \\
\hline
\end{tabular}

Table 5. Statistical analysis (ANOVA): elastic modulus and hardness.

\begin{tabular}{|c|c|c|c|c|c|c|c|}
\hline & Variable & $\begin{array}{l}\text { Degrees of } \\
\text { Freedom }\end{array}$ & $\begin{array}{c}\text { Sum of } \\
\text { squares effect }\end{array}$ & $\begin{array}{c}\text { Sum of } \\
\text { squares of } \\
\text { error }\end{array}$ & Statistics F & $\begin{array}{c}\text { Statistics } \\
\mathbf{P}\end{array}$ & Results \\
\hline \multirow{3}{*}{ 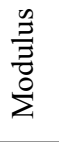 } & Material & 4778.56 & 1 & 4778.56 & 304.70 & 0.000 & Significant. \\
\hline & Load & 4.66 & 4 & 1.17 & 0.074 & 0.9898 & Not-signif. \\
\hline & Error & 1568.28 & 100 & 15.68 & - & - & - \\
\hline \multirow{3}{*}{ 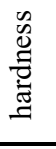 } & Material & 0.7558 & 1 & 0.7558 & 69.5601 & 0.000 & Significant. \\
\hline & Load & 0.0946 & 4 & 0.0237 & 2.1777 & 0.07690 & Not-signif. \\
\hline & Error & 1.0865 & 100 & 0.0109 & - & - & - \\
\hline
\end{tabular}

Table 6. Elastic modulus and hardness values for $32 \mathrm{mN}$ and $512 \mathrm{mN}$ of the indentations showed in Figure 9.

\begin{tabular}{|c|c|c|c|c|}
\hline \multirow{2}{*}{ Indented mark in Figure 9} & \multicolumn{2}{|c|}{$E$ (GPa) } & \multicolumn{2}{|c|}{$H(\mathrm{GPa})$} \\
\hline & $2 \mathrm{mN}$ & $512 \mathrm{mN}$ & $2 \mathrm{mN}$ & $512 \mathrm{mN}$ \\
\hline I & 4.3 & 5.2 & 0.07 & 0.07 \\
\hline III & 5.8 & 3.7 & 0.08 & 0.04 \\
\hline $\mathrm{V}$ & 2.3 & 3.3 & 0.03 & 0.03 \\
\hline VI & 5.9 & 3.5 & 0.08 & 0.06 \\
\hline VII & 3.9 & 3.5 & 0.05 & 0.06 \\
\hline
\end{tabular}

The results obtained for the five indentations were very similar and approximately 4.4 GPa (Table 4). In indentation V (Figure 9), which presented a surface defect close by, a modulus value of $2.3 \mathrm{GPa}$ was measured. Indentations III and VI (Figure 9) presented values of 5.8 and 5.9 GPa, respectively. Measurements at indentations II and IV (Figure 9), where superficial defects were also observed, could not be performed. Indentations I and VII (Figure 9) achieved values of 4.3 and $3.9 \mathrm{GPa}$, respectively. These results are presented in Table 6 for loads of $2 \mathrm{mN}$ and $512 \mathrm{mN}$. Indentations I and V showed increases in the elastic modulus when the load was increased to $512 \mathrm{mN}$, while the opposite occurred for indentations III, VI and VII. This increase in the elastic modulus occurs due to contributions from lower layers, while decreases are the result of fractures.

The samples were embedded in a carbon-containing resin, which presented a mean elastic modulus of $3.23 \pm 0.07 \mathrm{GPa}$ and mean hardness of $0.18 \pm 0.002 \mathrm{GPa}$. It is important to highlight that the morphology and mechanical 
properties of the resin are quite different from the C-S-H and C-S-H/PMA samples (Figure 10) and affirm that the resin did not influence these results. The indentation mark shown in Figure 9 refers to the largest load of $512 \mathrm{mN}$. The area covered by the minimum load of $1 \mathrm{mN}$ is very small, so the likelihood of two distinct regions occurring is minimal. Figures 5 and 8 show that both the hardness and elastic modulus did not vary according to the load applied and, thus, according to the depth of penetration. As the applied load increases, the probability of the indenter hitting a pore increases, since an increase in the contact area and the projected contact area also occurs. Assuming that the indenter hit a pore of a size that was visible in the microscopy images, the values of hardness and elastic modulus would certainly have decreased. Another factor that encouraged the use of a high load for the indentations $(512 \mathrm{mN})$ was the need to investigate the homogeneity of the C-S-H/PMA nanocomposite, which proved to be homogeneous and showed no significant differences in behavior regarding the load and area of coverage. An additional factor that could have influenced the micro-nanomechanical behavior is excess polymer not incorporated into the matrix, however, it is important to clarify that a small quantity of the polymer was used and that the $\mathrm{C}-\mathrm{S}-\mathrm{H}$, in gel form, was washed with acetone and filtered to remove free PMA before being dried.

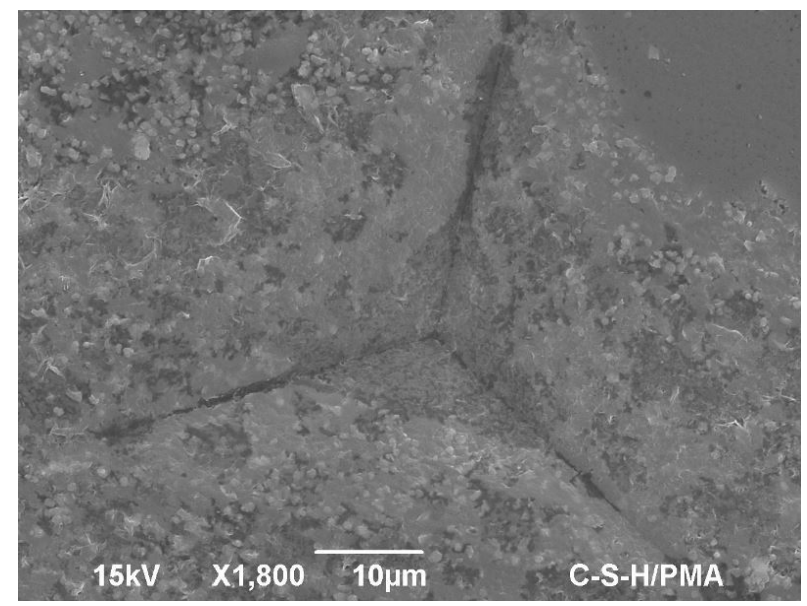

Figure 10. C-S-H/PMA SEM micrograph showing one indentation (matrix 2).

Other works have shown changes in the structure of the C-S-H/PDC-cationic polymer that influenced its structure and nanomechanical behavior, such that the presence of PDC in C-S-H affected both its nano (intercalation between the C-S-H lamellae) and mesostructure (C-S-H particles packing density) [18]. When evaluating the effect of the polymer of PVA-neutral [19], a significant change was verified in the nanomechanical properties of C-S-H, resulting in reduced elastic modulus and hardness. However, the set of results presented did not confirm the intercalation of PVA in the interlayer space of C-S-H, rather it confirmed the formation of a C-S-H/PVA mesocomposite, which presented changes in structural packing - in the midst of the PVA polymer film - and in nanomechanical properties.

It is also worth emphasizing that the values obtained for pure C-S-H fall within the same range as the nanoindentation measurements for C-S-H in hydrating Portland cement systems [25]-[27]. The accentuated decrease in elastic modulus of synthesized C-S-H in the presence of PMA could be due to the particle packing density [26] or surface roughness. In order to minimize the effect of surface roughness, higher loads must be applied.

Micrographs (SEM) showed different morphological structures for C-S-H/PMA (Figure 11) and C-S-H (Figure 12). Alterations in the nanostructure formation of C-S-H/PMA were verified by TEM (Figure 13), indicating different structuring for C-S-H (Figure 14). All the images obtained showed this behavior. It is well known that C-S-H is produced by the packing of elementary nanosized particles and that low and high density C-S-H differ according to their aggregation density [25]-[27]. Thus, it can be concluded that any significant alteration in the mechanical properties is due to the packing density of the C-S-H particles in the presence of PMA, as determined qualitatively by TEM. 


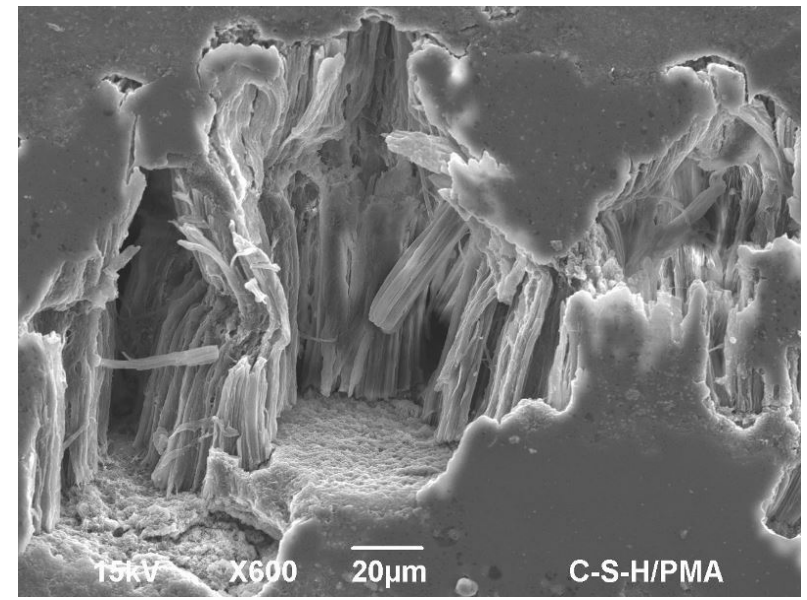

Figure 11. C-S-H/PMA SEM micrograph showing morphology of the microstructure.

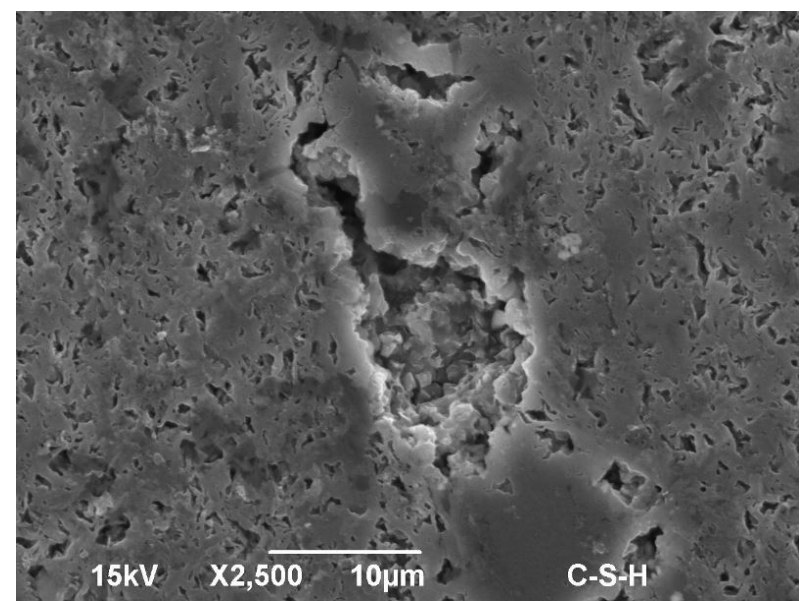

Figure 12. C-S-H SEM micrograph showing morphology of the microstructure.

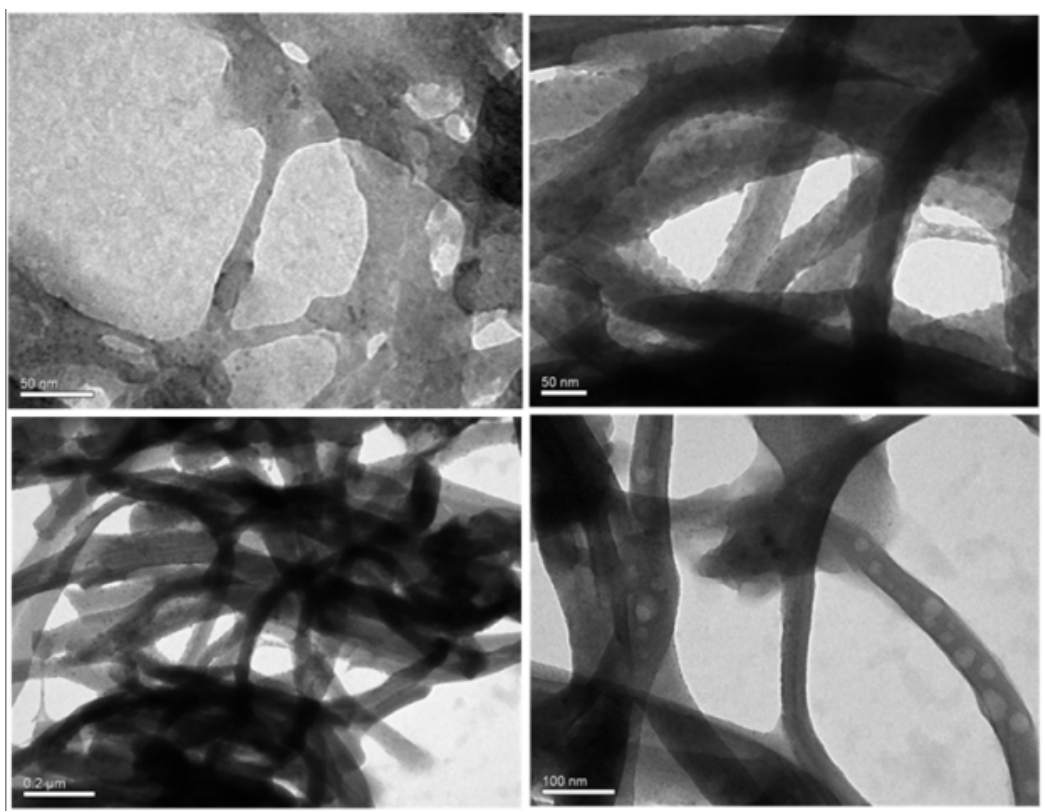

Figure 13. C-S-H/PMA (a, b) TEM micrographs. 


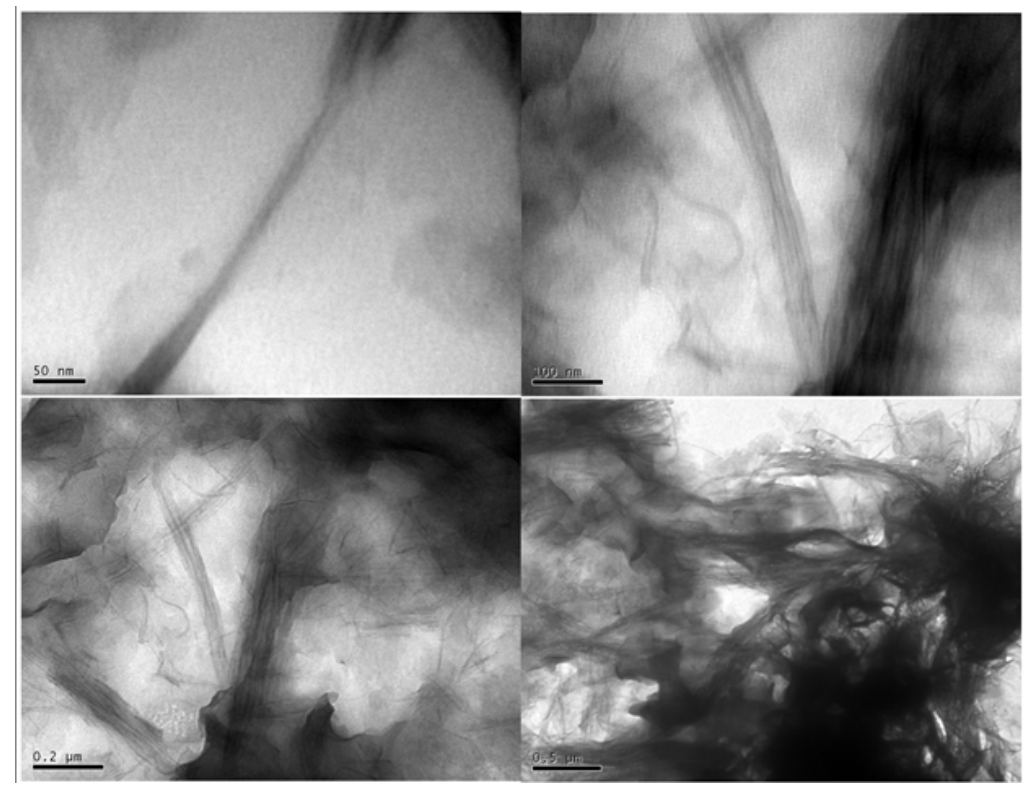

Figure 14. C-S-H TEM micrographs.

These results do not exclude the possibility that PMA can increase the cohesion of C-S-H, especially considering its application in the structure of hydrated Portland cement and its effect on a longer drying time. Lee and Rhee [28] used synthesis to verify poly(methyl methacrylate) $/ \mathrm{SiO}_{2}-\mathrm{CaO}$ nanocomposites using dimethyldiethoxysilane and tetraethoxysilane, which produced two and four siloxane linkages, respectively, after a sol-gel reaction. This nanocomposite can potentially be applied as a filler material of PMMA bone cement and dental composite resin because of its good apatite-forming ability and improved fracture toughness [28]. On the other hand, the reduction in the mechanical properties of cement obtained in this research, are indicative of lower efficiency and, consequently, higher cost for the same structural performance.

The strong influence of PMA on the mesostructure and nanomechanical properties of C-S-H is evident. These properties and attempts at manipulating the cement nanostructure contribute to the development of nanotechnology applied to more efficient materials [29].

\section{CONCLUSIONS}

The main results regarding the nanostructural changes in C-S-H modified with PMA are described below:

- The addition of PMA to C-S-H resulted in an increase in interplanar distance, from $1.53 \mathrm{~nm}$ to $1.64 \mathrm{~nm}$. These values are lower than those previously described by Matsuyama and Young [12] and similar to those reported by Merlin et al. [6] for other anionic polymers. This small increase in interplanar distance is not considered to be the intercalation of the polymer;

- A significant change was verified in the micro-nanomechanical properties of C-S-H with PMA, resulting in reduction in the elastic modulus and hardness. This reduction of approximately $67 \%$ occurred due to the structuring of lower density particles of C-S-H and the presence of the polymer, indicating the formation of a mesocomposite. The formation of a differentiated structure, with increased C-S-H porosity, was observed.

The set of results presented do not confirm the intercalation of PMA in the interlayer space of C-S-H, rather it confirms the formation of a C-S-H/PMA mesocomposite, which presented changes in structural packing and in micronanomechanical properties. 


\section{ACKNOWLEDGEMENTS}

The authors acknowledge the financial support of the CNPq (National Council of Technological and Scientific Development) and the Central Laboratory of Electronic Microscopy of the Federal University of Santa Catarina (LCME-UFSC) for the SEM and TEM micrographs.

\section{REFERENCES}

[1] I. Richardson, "The calcium silicate hydrates," Cement Concr. Res., vol. 38, no. 2, pp. 137-158, 2008, http://dx.doi.org/10.1016/j.cemconres.2007.11.005.

[2] J. J. Thomas, H. M. Jennings, and A. J. Allen, "Relationships between composition and density of tobermorite, jennite, and nanoscale CaO-SiO2- H2O," J. Phys. Chem. C, vol. 114, no. 17, pp. 7594-7601, 2010, http://dx.doi.org/10.1021/jp910733x.

[3] H. Manzano, J. Dolado, and A. Ayuela, "Elastic properties of the main species present in Portland cement pastes," Acta Mater., vol. 57, no. 5, pp. 1666-1674, 2009, http://dx.doi.org/10.1016/j.actamat.2008.12.007.

[4] F. Pelisser, P. Gleize, and A. Mikowski, "Effect of the $\mathrm{Ca} / \mathrm{Si}$ molar ratio on the micro/nanomechanical properties of synthetic C-S-H measured by nanoindentation," J. Phys. Chem. C, vol. 116, no. 32, pp. 17219-17227, 2012, http://dx.doi.org/10.1021/jp302240c.

[5] R. Pellenq and H. Van Damme, "Why does concrete set? The nature of cohesion forces in hardened cement-based materials," Mater. Res. Soc. Bull., vol. 29, no. 5, pp. 319-324, 2004, http://dx.doi.org/10.1557/mrs2004.97.

[6] F. Merlin, H. Lombois, S. Joly, N. Lequeux, J. Halary, and H. Van Damme, "Cement-polymer and clay-polymer nano- and mesocomposites: spotting the difference," J. Mater. Chem., vol. 12, no. 11, pp. 3308-3315, 2002, http://dx.doi.org/10.1039/B205279M.

[7] C. Glotzbach, D. Stephan, and M. Schmidt, "Measuring interparticle forces: evaluation of superplasticizers for microsilica via colloidal probe technique," Cement Concr. Compos., vol. 36, pp. 42-47, 2013, http://dx.doi.org/10.1016/j.cemconcomp.2012.11.007.

[8] T. Vulic, M. Hadnadjev-Kostic, O. Rudic, M. Radeka, R. Marinkovic-Neducin, and J. Ranogajec, "Improvement of cement-based mortars by application of photocatalytic active Ti-Zn-Al nanocomposites," Cement Concr. Compos., vol. 36, pp. 121-127, 2013, http://dx.doi.org/10.1016/j.cemconcomp.2012.07.005.

[9] A. M. Díez-Pascual, M. A. Gómez-Fatou, F. Ania, and A. Flores, "Nanoindentation in polymer nanocomposites," Prog. Mater. Sci., vol. 67, pp. 1-94, 2015, http://dx.doi.org/10.1016/j.pmatsci.2014.06.002.

[10] H. Matsuyama and J. F. Young, "The formation of C-S-H/Polymer complexes by hydration of reactive B-dicalcium silicate," Concr. Sc. Eng., vol. 1, no. 2, pp. 66-75, 1999.

[11] H. Matsuyama and J. F. Young, "The formation of C-S-H/polymer complexes with superplasticizing polymers," Concr. Sc. Eng., vol. 1 , no. 3, pp. 148-156, 1999.

[12] H. Matsuyama and J. F. Young, "Synthesis of calcium silicate hydrate/polymer complexes: Part I. Anionic and nonionic polymers," J. Mater. Res., vol. 14, no. 8, pp. 3379-3388, 1999, http://dx.doi.org/10.1557/JMR.1999.0458.

[13] H. Matsuyama and J. F. Young, "Synthesis of calcium silicate hydrate/polymer complexes: Part II. Cationic polymers and complex formation with different polymers," J. Mater. Res., vol. 14, no. 8, pp. 3389-3396, 1999, http://dx.doi.org/10.1557/JMR.1999.0459.

[14] H. Matsuyama and J. F. Young, "Intercalation of polymers in calcium silicate hydrate: a new synthetic approach to biocomposites," Chem. Mater., vol. 11, no. 1, pp. 16-19, 1999, http://dx.doi.org/10.1021/cm9805491.

[15] S. C. Mojumdar and L. Raki, "Preparation and properties of calcium silicate hydrate-poly(vinyl alcohol) nanocomposite materials," $J$. Therm. Anal. Calorim., vol. 82, no. 1, pp. 89-95, 2005, http://dx.doi.org/10.1007/s10973-005-0846-8.

[16] A. Mansur and H. Mansur, "Interface porcelain tile/PVA modified mortar: a novel nanostructure approach," J. Nanosci. Nanotechnol., vol. 9, no. 2, pp. 1071-1075, 2009, http://dx.doi.org/10.1166/jnn.2009.C090.

[17] J. J. Beaudoin, H. Dramé, L. Raki, and R. Alizadeh, "Formation and properties of C-S-H-PEG nano-structures," Mater. Struct., vol. 42, no. 7, pp. 1003-1014, 2009, http://dx.doi.org/10.1617/s11527-008-9439-x.

[18] F. Pelisser, P. J. P. Gleize, and A. Mikowski, "Effect of poly(diallyldimethylammonium chloride) on nanostructure and mechanical properties of calcium silicate hydrate," Mater. Sci. Eng. A, vol. 527, no. 26, pp. 7045-7049, 2010, http://dx.doi.org/10.1016/j.msea.2010.07.057.

[19] F. Pelisser, P. J. P. Gleize, and A. Mikowski, "Structure and micro-nanomechanical characterization of synthetic calcium-silicatehydrate with Poly(Vinyl Alcohol)," Cement Concr. Compos., vol. 48, pp. 1-8, 2014, http://dx.doi.org/10.1016/j.cemconcomp.2014.01.004.

[20] W. C. Oliver and G. M. Pharr, "An improved technique for determining hardness and elastic modulus using load and displacement sensing indentation experiments," J. Mater. Res., vol. 7, no. 6, pp. 1564-1583, 1992, http://dx.doi.org/10.1557/JMR.1992.1564.

[21] W. C. Oliver and G. M. Pharr, "Measurement of hardness and elastic modulus by instrumented indentation: Advances in understanding and refinements to methodology," J. Mater. Res., vol. 19, no. 1, pp. 3-20, 2004, http://dx.doi.org/10.1557/jmr.2004.19.1.3.

[22] F. R. Brotzen, "Mechanical testing of thin films," Int. Mater. Rev., vol. 39, no. 1, pp. 24-45, 1994, http://dx.doi.org/10.1179/imr.1994.39.1.24. 
[23] I. N. Sneddon, "The relation between load and penetration in the axisymmetric boussinesq problem for a punch of arbitrary profile," Int. J. Eng. Sci., vol. 3, no. 1, pp. 47-57, 1965, http://dx.doi.org/10.1016/0020-7225(65)90019-4.

[24] N. Y. Mostafa, A. A. Shaltout, H. Omar, and S. A. Abo-El-Enein, "Hydrothermal synthesis and characterization of aluminium and sulfate substituted 1.1nm tobermorites," J. Alloys Compd., vol. 467, no. 1-2, pp. 332-337, 2009, http://dx.doi.org/10.1016/j.jallcom.2007.11.130.

[25] G. Constantinides and F.-J. Ulm, "The nanogranular nature of C-S-H," J. Mech. Phys. Solids, vol. 55, no. 1, pp. 64-90, 2007, http://dx.doi.org/10.1016/j.jmps.2006.06.003.

[26] M. Vandamme, F.-J. Ulm, and P. Fonollosa, "Nanogranular packing of C-S-H at substochiometric conditions," Cement Concr. Res., vol. 40, no. 1, pp. 14-26, 2010, http://dx.doi.org/10.1016/j.cemconres.2009.09.017.

[27] H. M. Jennings, "Refinements to colloid model of CSH in cement: CM-II," Cement Concr. Res., vol. 38, no. 3, pp. 275-289, 2008, http://dx.doi.org/10.1016/j.cemconres.2007.10.006.

[28] K.-H. Lee and S.-H. Rhee, "The mechanical properties and bioactivity of poly(methyl methacrylate)/SiO2-CaO nanocomposite," Biomaterials, vol. 30, no. 20, pp. 3444-3449, 2009, http://dx.doi.org/10.1016/j.biomaterials.2009.03.002.

[29] M. Schmidt, K. Amrhein, T. Braun, C. Glotzbach, S. Kamaruddin, and R. Tänzer, "Nanotechnological improvement of structural materials - impact on material performance and structural design," Cement Concr. Compos., vol. 36, pp. 3-7, 2013, http://dx.doi.org/10.1016/j.cemconcomp.2012.11.003.

Author contributions: Fernando Pelisser: Conceptualization, Investigation, Writing-Original draft preparation, Methodology, Data curation, Writing- Reviewing and Editing. Philippe J. P. Gleize: Supervision, Conceptualization. Alexandre Mikowski: Visualization, Methodology, Data curation.

Editors: José Luiz Antunes de Oliveira e Sousa, Guilherme Aris Parsekian. 